\title{
Is there a future for clinical cytology?
}

\author{
DULCIE V COLEMAN
}

The growth and development of the cytology service in the United Kingdom from its pioneer status in the 1950s to its present strength were stimulated by a decision of the Ministry of Health in 1963. This was to provide a screening service for all women at risk of cervical cancer over $35 .^{1}$ This decision meant that the laboratory service had to be expanded if hospitals were to cope with the expected increase in the number of requests. Doctors and technicians were hastily recruited into cytology. They were drawn from a wide variety of backgrounds -married women doctors, science graduates, nurses, and school leavers-but few of them had laboratory experience and fewer still had a background knowledge of cytology. ${ }^{2}$ The Ministry acknowledged the urgent need for training and established five cytology training centres. The courses offered were short (lasting not more than 12 weeks), practical, and limited in their scope, providing only information useful for the analysis of the Papanicolaou smear in the light microscope.

Against this background of haste and expediency cytology has developed and, though the conditions have not been ideal, hospital laboratories have been able to meet the expected demand and over four million smears are now screened annually in the UK. Two-thirds of the 500 pathology laboratories in England offer a cytodiagnostic service and over 1000 laboratory personnel are now employed full time in this specialty ${ }^{3}$ In most laboratories the scope of the Papanicolaou method has been extended beyond screening for cervical cancer to include the examination of cells exfoliated from respiratory and urinary tracts and serous membranes for evidence of malignancy. Laboratories also interpret endoscopic brush specimens from the gastric and bronchial mucosa and fine-needle aspirates of cystic swellings and solid tumours. This wider application of the Papanicolaou technique shows the clinical value of cytology as a rapid, accurate, and non-invasive method of detecting malignant disease.

Though material from a wide variety of sites can be obtained for cytological investigation, diagnosis is based solely on the light microscope appearances of fixed and stained cells. While no one would deny the value of cell morphology as a basis for the identification of malignant cells in cytological smears, the classification of neoplastic lesions on these grounds alone is limited. There is considerable scope in cytology to increase the precision of tumour diagnosis by extending the investigation of cells to include an assessment of their functional properties and ultrastructure. Pathologists who supervise the service and clinicians who use it should be aware of its potential for development in this direction.

\section{Potential for development}

The examination of the ultrastructural appearances and functional indices of tumour cells using electron microscopic, immunocytochemical, and cytogenetic methods would provide a broader basis for cytological reporting than light microscopy

\footnotetext{
St Mary's Hospital, London W2 1NY

DULCIE V COLEMAN, senior lecturer in clinical cytology and cytogenetics
}

alone. For example, cytogenetic analysis of the cells of serous fluids $^{45}$ can be useful, especially in those effusions where the differential diagnosis between malignant cells and reactive mesothelial cells by light microscopy is difficult. Similarly, the reprocessing of fixed and stained cells selected from mounted cytological smears for transmission electron microscopy ${ }^{6}$ will permit the identification of cell organelles and structural elements not apparent under the light microscope. Ultrastructural examination of selected cells will show the presence of virus particle, ${ }^{6}$ neurosecretory granules, ${ }^{7}$ microvillae, etc, which will encourage precision in cytological reporting.

In addition, the demonstration of tumour markers by immunocytochemical methods has a potential application to cytology, particularly to fresh aspirates of solid tumours of breast, thyroid, and prostate. Moreover, new methods of cell separation using lectins and two-phase aqueous polymer systems ${ }^{8}$ need to be explored. The application of these combined techniques to cytological material would permit the development of systems of tumour classification, which could reflect more accurately the malignant state of the lesion and effectively improve clinical management.

\section{Problems of training and professional qualifications}

The introduction of additional investigative techniques into routine cytology would represent a major advance in what is at the moment a limited field of pathological investigation. In practical terms, however, fundamental changes would have to occur in the training of cytologists before these investigations could be introduced. The application and interpretation of these recently developed methods of investigation demand a high degree of technical skill by the laboratory staff, who would require an in-depth knowledge of the cell and methods of evaluating its functions.

Unfortunately, these scientific requirements cannot be met by most laboratory personnel working in cytology because their training and work experience are so restricted. Moreover, there is no way in which they can extend their knowledge without leaving the discipline, for they do not qualify for the broader professional training available to their colleagues in other branches of pathology. This anomaly is undoubtedly the result of the short-sighted policy adopted 15 years ago when laboratory personnel were recruited into the newly developing specialty of cytology without first ensuring their proper integration into the mainstream of technical training. Thus the discipline is deprived of the highly qualified technical staff who would be able to introduce new methodology into cytology.

The solution to the staffing problem was thought to be employing laboratory personnel in non-career grades. A cytology screener grade was created for cytotechnicians who did not qualify for promotion on the medical laboratory scientific officer scale. This policy has decreased even further the likelihood of highly qualified staff entering the discipline, as the people attracted to these non-career appointments have tended to be those without a formal training in pathology. By discouraging the selection of individuals with a broad scientific background the status of cytology in clinical and academic pathology is diminished and the further development of the discipline as a clinical diagnostic tool is retarded.

This trend could be reversed by introducing a training 
course in cytology characterised by qualifying examinations leading to recognised professional qualifications. The present system of training medical laboratory scientists in morbid anatomy and histopathology would require only minor modification to accommodate individuals with a special interest in cytology. Existing training programmes in histopathology are a combination of formal courses and work experience and include instruction in cytology at all levels. The cytology component of the courses, however, is small and inappropriate for candidates whose principal work is in a cytology laboratory. A training programme for cytologists is required which would relate closely to their work experience. Though there is a common theoretical basis for histopathological and cytological investigation and formal courses could be closely integrated, the disciplines are distinct in terms of work experience and separate qualifying examinations are essential.

\section{Conclusion}

Cytological investigation has made a major contribution to current concepts of cancer as a detectable disease in its early stages. The scope for further advances in clinical diagnosis and research is wide, but depends on recruiting highly skilled scientific staff capable of adapting new techniques and methodology to cytological material. Training cytologists to standards equivalent to those in other branches of pathology would be a major step toward ensuring the future development of the discipline. This is essential if cytology is to continue to contribute new ideas to medical practice and to fulfil its potential as a growth area of clinical pathology.

\section{References}

${ }^{1}$ Ministry of Health, Annual Report of the Chief Medical Officer. London, HMSO, 1963.

${ }^{2}$ McInroy, R A, British Medical fournal, 1966, 1, 1472.

3 Buttolph, M A, Fournal of Clinical Pathology, 1977, 30, 1103.

4 Dewald, G, et al, The New England fournal of Medicine, 1976, 295, 1494.

5 Benedict, W F, and Porter, I H, Acta Cytologica, 1972, 16, 304.

6 Coleman, D V, et al, fournal of Clinical Pathology, 1977, 30, 1103.

7 Gould, V E, and Chejfec, G, Human Pathology, 1978, 9, 377.

${ }^{8}$ Gersten, D M, and Bosmann, A B, Experimental Cell Research, 1974, 87, 73.

(Accepted 12 March 1979)

\section{Scotland}

\section{Allocation and expenditure}

The following table gives the financial allocation to area health boards in Scotland for 1977-8 and 1978-9, together with the actual expenditure for 1977-8 and the current spending to the latest available date for 1978-9.

\begin{tabular}{|c|c|c|c|c|c|c|c|c|}
\hline \multirow{3}{*}{ Health boards } & \multicolumn{4}{|c|}{$1977-8$} & \multicolumn{4}{|c|}{$1978-9$} \\
\hline & \multicolumn{2}{|c|}{ Revenue } & \multicolumn{2}{|c|}{ Capital } & \multicolumn{2}{|c|}{ Revenue } & \multicolumn{2}{|c|}{ Capital } \\
\hline & Allocation & Expenditure & Allocation & Expenditure & $\begin{array}{l}\text { Estimated } \\
\text { final } \\
\text { allocation }\end{array}$ & $\begin{array}{c}\text { Estimated } \\
\text { expenditure }\end{array}$ & $\begin{array}{l}\text { Estimated } \\
\text { final } \\
\text { allocation }\end{array}$ & $\begin{array}{l}\text { Estimated } \\
\text { expenditure }\end{array}$ \\
\hline $\begin{array}{l}\text { Argyll and Clyde } \\
\text { Ayrshire and Arran } \\
\text { Borders } \\
\text { Dumfries and Galloway } \\
\text { Fife } \\
\text { Forth Valley } \\
\text { Grampian } \\
\text { Glasgow } \\
\text { Highland } \\
\text { Lanarkshire } \\
\text { Lothian } \\
\text { Orkney } \\
\text { Shetland } \\
\text { Tayside } \\
\text { Western Isles }\end{array}$ & $\begin{aligned} 6000 \\
38678 \\
23448 \\
7579 \\
13572 \\
24692 \\
24631 \\
46844 \\
149764 \\
20235 \\
42875 \\
89565 \\
1220 \\
1501 \\
56015 \\
2296\end{aligned}$ & $\begin{array}{r}£ 000 \\
38661 \\
23003 \\
7536 \\
13284 \\
24485 \\
24444 \\
46298 \\
149740 \\
20066 \\
42764 \\
89409 \\
1201 \\
1501 \\
55668 \\
2260\end{array}$ & $\begin{array}{rl}6000 \\
4572 \\
3993 \\
1066 \\
1015 \\
1176 \\
11007 \\
2325 \\
9065 \\
11757 \\
2952 \\
6970 \\
& 130 \\
& 90 \\
2 & 175 \\
& 268\end{array}$ & $\begin{array}{rl}6000 \\
4648 \\
4 & 068 \\
1 & 073 \\
& 529 \\
1 & 205 \\
1 & 069 \\
2 & 113 \\
8 & 935 \\
1 & 757 \\
3 & 061 \\
7 & 034 \\
& 116 \\
& 84 \\
2 & 147 \\
& 328\end{array}$ & $\begin{array}{r}£ 000 \\
44551 \\
27504 \\
8503 \\
15593 \\
28274 \\
28028 \\
52906 \\
170200 \\
23301 \\
48502 \\
101071 \\
1467 \\
1728 \\
62901 \\
2711\end{array}$ & \begin{aligned} \multicolumn{1}{c}{0000} \\
44456 \\
27124 \\
8463 \\
15313 \\
27344 \\
27758 \\
52481 \\
170096 \\
23141 \\
48482 \\
100656 \\
1460 \\
1720 \\
62295 \\
2700\end{aligned} & $\begin{array}{r}f 000 \\
7538 \\
5529 \\
1101 \\
570 \\
1727 \\
2090 \\
2910 \\
11357 \\
2529 \\
2170 \\
7898 \\
295 \\
234 \\
4278 \\
739\end{array}$ & $\begin{array}{r}6000 \\
5778 \\
5218 \\
1201 \\
570 \\
1727 \\
1852 \\
2886 \\
10830 \\
2529 \\
2170 \\
7661 \\
215 \\
150 \\
3837 \\
626\end{array}$ \\
\hline
\end{tabular}

\section{Joint Consultants Committee -continued from page 1030}

for the working party report and then comment on it.

\section{Private patients}

Mr David Bolt reported that the CMO had submitted the DHSS's proposals for introducing arrangements for admitting private patients under the NHS Act 1977 which set up the Health Services Board. Implementation of section 59 would afford private patients admission or access to NHS accommodation or services for investigation, diagnosis, or treatment of a specialised nature or needing specialised equipment or skill not reasonably accessible privately outside the NHS. The profession had submitted an indicative list in November 1977 but the Department thought that this was "based on a fairly broad interpretation of what was meant by specialised."

The CMO had asked for views on the latest proposals and on the investigations, diagnoses, and treatments which should be included in the comprehensive list. There would, $\mathrm{Mr}$ Bolt said, need to be detailed discussions on the subject.

There would also, he said, have to be further discussions on a draft circular about extending common waiting lists to all patients. It had already been agreed that there should be a common waiting list for all urgent cases (6 January, p 68) and health authorities had been asked to discuss with their consultant staff the steps which would have to be taken to extend the list and to report by July. The draft circular gave the impression, $\mathrm{Mr}$ Bolt told the committee, that the profession had agreed to an extension of the common waiting list and all that was needed was for health authorities to tell the Secretary of State how to overcome local difficulties. That was not so.

\section{Aggressive podiatrists}

The committee's deputy secretary, Dr A Gilmour, had written to the CMO about the JCC's concern at the way the practice of podiatry was developing into areas previously regarded as restricted to qualified medical practitioners. Dr M M Burrows (CCHMS) told the committee that several organisations represented chiropody and the podiatrists were among the most aggressive who wanted to make inroads into surgery. The BMA should discuss the matter with the Society of Chiropodists. In the NHS chiropodists had to have proper training and be registered. Anyone could practise privately and the society would like to see that changed; the JCC should support them. Mr R H B Mills (Wales) suggested that doctors should refuse to give anaesthetics for these practitioners. The committee decided to tell the CMO that it would not tolerate the appointment of podiatrists in the NHS. 